\title{
Changes in cerebral blood flow and vasoreactivity in response to acetazolamide in patients with transient global amnesia
}

Yasuo Sakashita, Masanobu Kanai, Tatsuho Sugimoto, Suzuka Taki, Masaharu Takamori

Department of

Neurology

Y Sakashita

Department of Internal Medicine

M Kanai

T Sugimoto

Department of Radiology, Tonami General Hospital, Tonami, Toyama, Japan

S Taki

Department of Neurology, Kanazawa University School of Medicine, Kanazawa, Japan

M Takamori

Correspondence to: Dr Yasuo Sakashita, Department of Neurology, Tonami General Hospital, 1-61 Shintomi-cho, Tonami, Toyama 939-13, Japan.

Received 9 December 1996 and in revised form 24 February 1997

Accepted 14 May 1997

\begin{abstract}
Objective-Previous reports about changes in cerebral blood flow (CBF) in transient global amnesia disclosed decreased flow in some parts of the brain. However, CBF analyses in most reports were qualitative but not quantitative. The purpose of this study was to determine changes in CBF in transient global amnesia.

Methods-The CBF was measured and the vasoreactive response to acetazolamide was evaluated in six patients with transient global amnesia using technetium-99m hexamethylpropylene amine oxime singlephoton emission computed tomography (SPECT). The CBF was measured during an attack in two patients and soon after an attack in the other four. About one month later, $\mathrm{CBF}$ was re-evaluated in each patient.

Results-Two patients examined during an attack and one patient examined five hours after an attack had increased blood flow in the occipital cortex and cerebellum. Three patients examined at six to 10 hours after an attack had decreased blood flow in the thalamus, cerebellum, or putamen. These abnormalities of blood flow almost disappeared in all patients one month after onset. The vasodilatory response to acetazolamide, which was evaluated initially using SPECT, was poor in areas of increased blood flow. By the second evaluation of CBF with acetazolamide, the vasodilatory response had returned to normal.

Conclusions-In a patient with transient global amnesia, CBF increased in the vertebrobasilar territory during the attack and decreased afterwards. The vasodilatory response to acetazolamide may be impaired in the parts of the brain with increased blood flow. It is suggested that transient global amnesia is distinct from migraine but may share the same underlying mechanism.
\end{abstract}

\section{(F Neurol Neurosurg Psychiatry 1997;63:605-610)}

Keywords: amnesia; migraine; cerebrovascular circulation; physiopathology; acetazolamide

Transient global amnesia is an episodic dysfunction of declarative memory for recent events without neurological signs or symp- toms. ${ }^{1}$ The patient cannot recall the verbal or non-verbal materials presented only minutes before, and he often repeats the same question many times. Whereas there are numerous studies on the aetiology of transient global amnesia, results are conflicting. The disagreement seems to result from three major investigative drawbacks. Firstly, the reported clinical syndromes were heterogeneous. Some authors ${ }^{2-4}$ included patients who had neurological symptoms or signs other than transient memory disturbances. The patient with pure transient global amnesia almost always displays an episode of temporary isolated amnesia and amnesic syndromes must be differentiated from pure transient global amnesia for further investigation. Absence of associated neurological deficits, such as aphasia, visual field defect, eye movement abnormalities or hemiparesis, is an essential criterion. There must be no evidence of head trauma, seizure, loss of consciousness, or overdose of some types of drugs. There should be no evidence of transient vertebrobasilar hypoperfusion caused by cardiac arrhythmia, coronary angiography, or cerebral angiography. Secondly, the intervals between the onset of transient global amnesia to the performance of diagnostic neuroimaging procedures were varied. The amnesia in transient global amnesia is, by definition, transient, and the prognosis is good. ${ }^{15}$ Caplan $^{5}$ analysed 360 attacks and estimated the average attack duration as 7.4 hours. In that study, only $5 \%$ of the patients had attacks that lasted a day or longer. ${ }^{5}$ Whereas the objective was to elucidate the aetiology or mechanism of transient global amnesia, some procedures were done long after the onset of it. ${ }^{367}$ These could be uninformative because the abnormality may have disappeared. Thirdly, most of the reports on the change in cerebral blood flow (CBF) in transient global amnesia were only qualitative. Few studies have used quantitative methods and investigated the patient with transient global amnesia during or soon after an attack. There are few reports of pure cases of transient global amnesia, in which changes in $\mathrm{CBF}$ was clearly shown by early and follow up quantitative analyses of CBF by single photon emission computed tomography (SPECT). Goldenberg et $a l^{\beta}$ showed transient ischaemia in the thalamus, and Sakashita et $a l^{9}$ showed a transient decrease in perfusion in the left inferior temporal cortex, bilateral thalami, and right hippocampus. The changes in both blood 
Table 1 Profile of patients

\begin{tabular}{|c|c|c|c|c|c|c|c|}
\hline $\begin{array}{l}\text { Patient } \\
\text { No }\end{array}$ & $\begin{array}{l}\text { Age } \\
\text { (y) }\end{array}$ & Sex & $\begin{array}{l}\text { Anterograde } \\
\text { amnesia } \\
\text { (h) }\end{array}$ & $\begin{array}{l}\text { Retrograde } \\
\text { amnesia } \\
\text { (h) }\end{array}$ & $\begin{array}{l}\text { From onset to } \\
\text { first } \\
\text { application of } \\
\text { SPECT (h) }\end{array}$ & $\begin{array}{l}\text { From onset to } \\
\text { second } \\
\text { application of } \\
\text { SPECT (days) }\end{array}$ & $\begin{array}{l}\text { Relevant } \\
\text { medical } \\
\text { history }\end{array}$ \\
\hline 1 & 57 & $\mathrm{~F}$ & 6 & 15 & 3 & 28 & None \\
\hline 2 & 56 & $\mathrm{~F}$ & 16 & 3 & 12 & 24 & Lung cancer \\
\hline 3 & 63 & M & 21 & 3 & 26 & 29 & None \\
\hline 4 & 53 & $\mathrm{~F}$ & 14 & 3 & 20 & 25 & None \\
\hline 5 & 59 & $\mathrm{~F}$ & 16 & 5 & 23 & 29 & None \\
\hline 6 & 63 & $\mathrm{~F}$ & 13 & 3 & 23 & 36 & Hypertension \\
\hline
\end{tabular}

flow and oxygen metabolism may be transient in patients with transient global amnesia.

Acetazolamide is a potent carbonic anhydrase inhibitor that produces a physiological inhibition of carbonic anhydrase in the red blood cells within one minute of the rapid intravenous injection of $1 \mathrm{~g}$ of the drug. ${ }^{10}$ The intravenous injection of acetazolamide to normal subjects increases cerebral as well as cerebellar blood flow within minutes. ${ }^{11}{ }^{12}$ Acetazolamide has been used to test cerebral vasodilatory capacity. ${ }^{12}$ However, vasoreactivity to acetazolamide in patients with transient global amnesia has not been reported.

We report the quantitative analyses of changes in $\mathrm{CBF}$ and vasoreactivity with acetazolamide in six patients with pure transient global amnesia studied with technetium-99m $\left.{ }^{99 \mathrm{~m}} \mathrm{Tc}\right)$ hexamethylpropylene amine oxime (HMPAO) SPECT.

\section{Patients and methods}

PATIENTS

We evaluated six Japanese patients with transient global amnesia, one man and five women, age range 56 to 63 years, mean 58.5 years (table 1). All had profound memory disturbances for recent events without neurological signs or symptoms. The amnesia was transient and the patients recovered from amnesia completely. All were right handed. No lesions in the brain were found in any patient by CT or MRI.

MEASUREMENTS OF CEREBRAL BLOOD FLOW WITH SPECT

Measurements of CBF using ${ }^{99 \mathrm{~m}} \mathrm{Tc}$ HMPAO without and with acetazolamide stress were performed twice in each patient. The first application of SPECT was during the attack in patients 1 and 2 and soon after the attack (after five to 10 hours) in the other four patients. The second SPECT was done 24 to 36 days after the onset of the attack. The SPECT system consisted of a rotating gamma camera (GCA901, Toshiba, Tokyo, Japan) and an image processing minicomputer (GMS-550U, Toshiba). ${ }^{99 \mathrm{~m}} \mathrm{Tc}$ HMPAO SPECT both with and without acetazolamide stress was done according to the following procedure. For measurement of CBF without acetazolamide, acquisition of projection data was begun 15 minutes after the intravenous injection of 740 $\mathrm{MBq}{ }^{99 \mathrm{~m}} \mathrm{Tc}$ HMPAO. Data were collected for 60 angles $\left(6^{\circ}\right.$ step, $\left.360^{\circ}\right)$ with 30 seconds per angle. Data were reconstructed by filtered back projection using Butterworth filters. After the data acquisition, $1 \mathrm{~g}$ acetazolamide was parenterally injected and after 10 minutes an additional $740 \mathrm{MBq}{ }^{99 \mathrm{~m}} \mathrm{Tc}$ HMPAO was injected. Data accumulation for acetazolamide stressed CBF measurement was started 15 minutes later. Quantitative measurements of regional blood flow were performed using the method reported by Matsuda et $a l,{ }^{14}$ which employed Lassen's correction algorithm for the linearisation of a curvelinear relation between the radioactivity in the brain and blood flow as seen with SPECT images. This quantitative method is non-invasive and does not require any blood sampling. ${ }^{14}$ For quantification of $\mathrm{CBF}$ in each patient, regions of interest were drawn over the bilateral superior frontal, middle frontal, inferior frontal, superior temporal, inferior temporal, superior parietal cortices, inferior parietal, and occipital cortices, thalami, putamens, hippocampi, and parahippocampal gyri, and cerebellar cortices.

\section{Results}

REGIONAL CBF MEASUREMENT BY SPECT

WITHOUT ACETAZOLAMIDE STRESS

Figure 1 shows the results of measurement of $\mathrm{CBF}$ without acetazolamide stress in the first and second applications of SPECT. Normal regional $\mathrm{CBF}$ values were obtained from age matched normal subjects. ${ }^{14}$ When the regional $\mathrm{CBF}$ was more or less than the mean $\pm 3 \mathrm{SD}$, it was judged to be abnormal. In the first application of SPECT, patients 1 and 2, who were examined during the attack, and patient 3, who was examined five hours after the attack, showed increased blood flow in some regions. Regional blood flow in the occipital cortex and cerebellum was increased in these three patients. Patients 2 and 3 also showed increased flow in the frontal, temporal, and parietal cortices. These abnormalities had almost returned to normal on application of follow up SPECT. In patients 4, 5, and 6, who were examined six to 10 hours after the amnesic period, there were some regions that showed decreased blood flow. Blood flow was decreased in the putamens in patient 4 , in the bilateral cerebellum and right thalamus in patient 5 , and in the bilateral temporal cortices and right hippocampus and parahippocampal gyrus in patient 6 . These abnormalities had also returned to normal on follow up SPECT.

\section{REGIONAL CBF MEASUREMENT BY SPECT WITH} ACETAZOLAMIDE STRESS

Figure 1 shows the results of regional CBF measurement at baseline and after acetazolamide injection. We considered that vasoreactivity to acetazolamide was impaired when a percentage increase was less than $10 \% .{ }^{11-16}$ In the first application of SPECT in patients 1,2 , and 3 , the regional blood flow was increased in the occipital cortices and cerebellum, and the vasoreactivity to acetazolamide was impaired in these regions. The superior temporal cortex in patient 1 , the bilateral occipital cortices and left cerebellum in patient 2, and the bilateral thalami, bilateral hippocampi and parahippocampal gyri, left cerebellar cortex, and left middle frontal cortex in patient 3 also had both increased blood flow and impaired vasoreactivity. In the other three patients, examined six to 
$\frac{\text { Frontal } C X}{\text { Superior Middle Inferior }} \frac{\text { Temporal } C_{X}}{\text { Superior Inferior }} \frac{\text { Parietal } C_{X}}{\text { Superior Inferior }}$ Occipital CX Thalamus Putamen

Hippocampus

छ
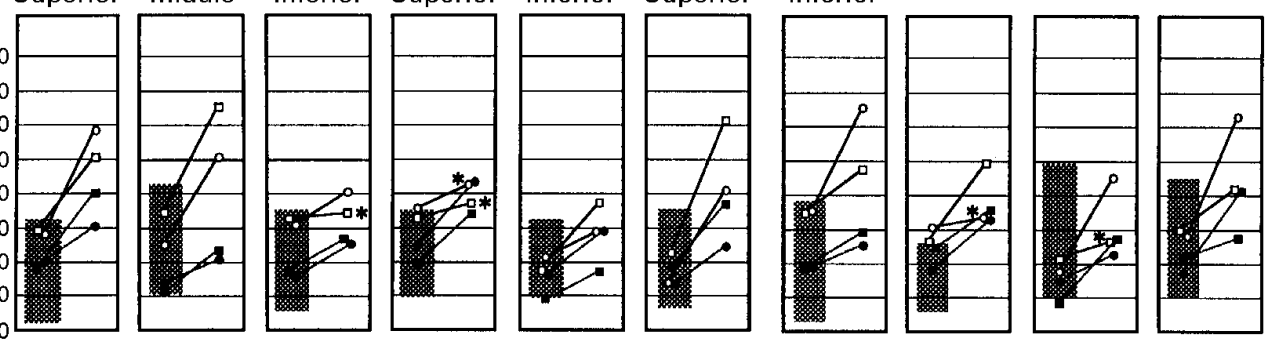

parahipp GY
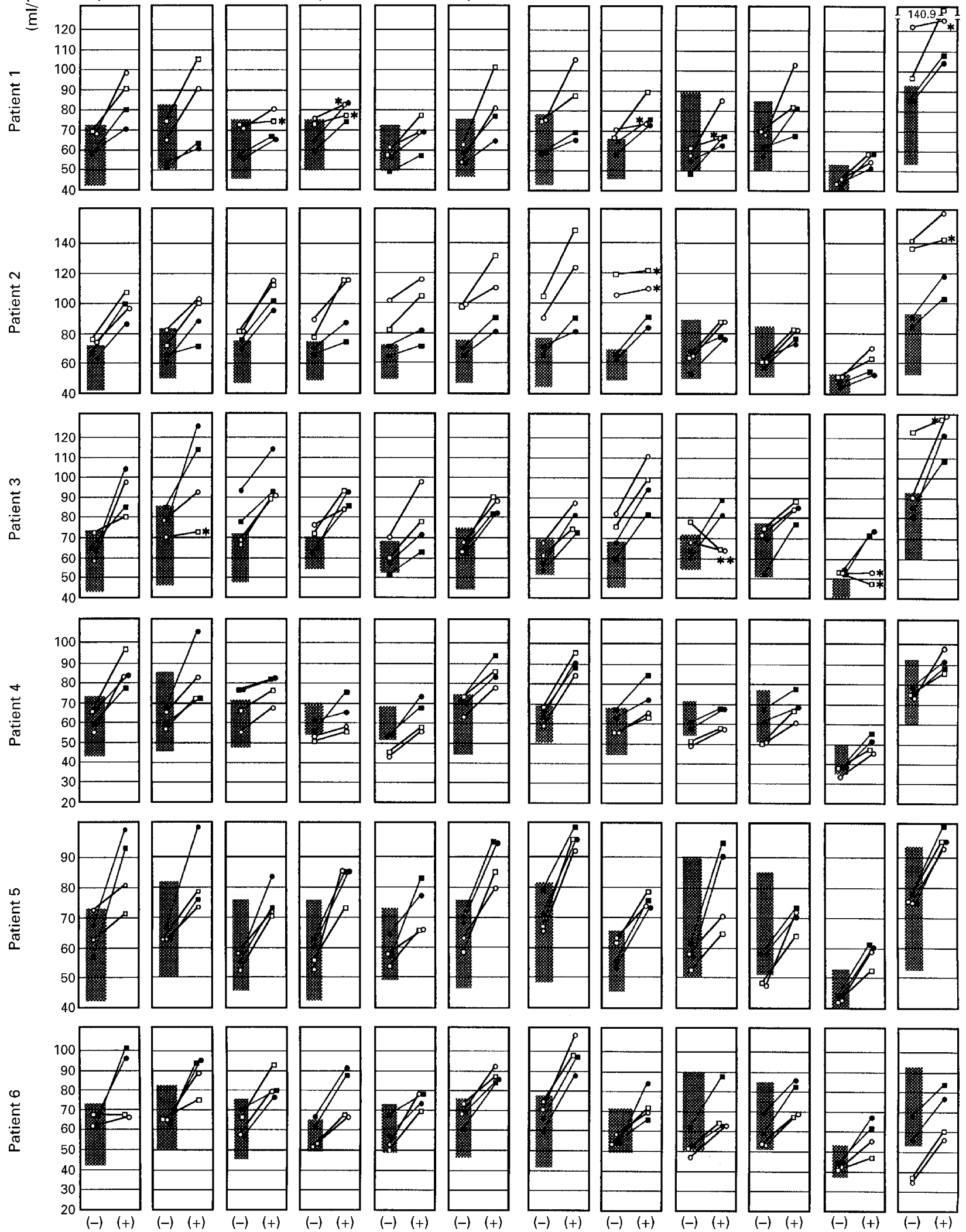

Acetazolamide

Figure 1 Results of regional CBF ( $r C B F$ ) measurements in the first and second application of SPECT in patients with transient global amnesia. Normal values were obtained from age matched normal subjects and shaded areas show mean (3SD) $r C B F$ in each region. Open squares indicate $r C B F$ in the left hemisphere and open circles indicate $r C B F$ in the right hemisphere in the first application of SPECT. Closed squares indicate rCBF in the left hemisphere and closed circles indicate $r C B F$ in the right hemisphere in the second application of SPECT. * indicates a percentage increase of $r C B F<10 \%$ from

baseline after acetazolamide injection. (-) without acetazolamide injection; $(+)$ with acetazolamide injection. Cx=cortex; parahipp gy=parahippocampal gyrus. 

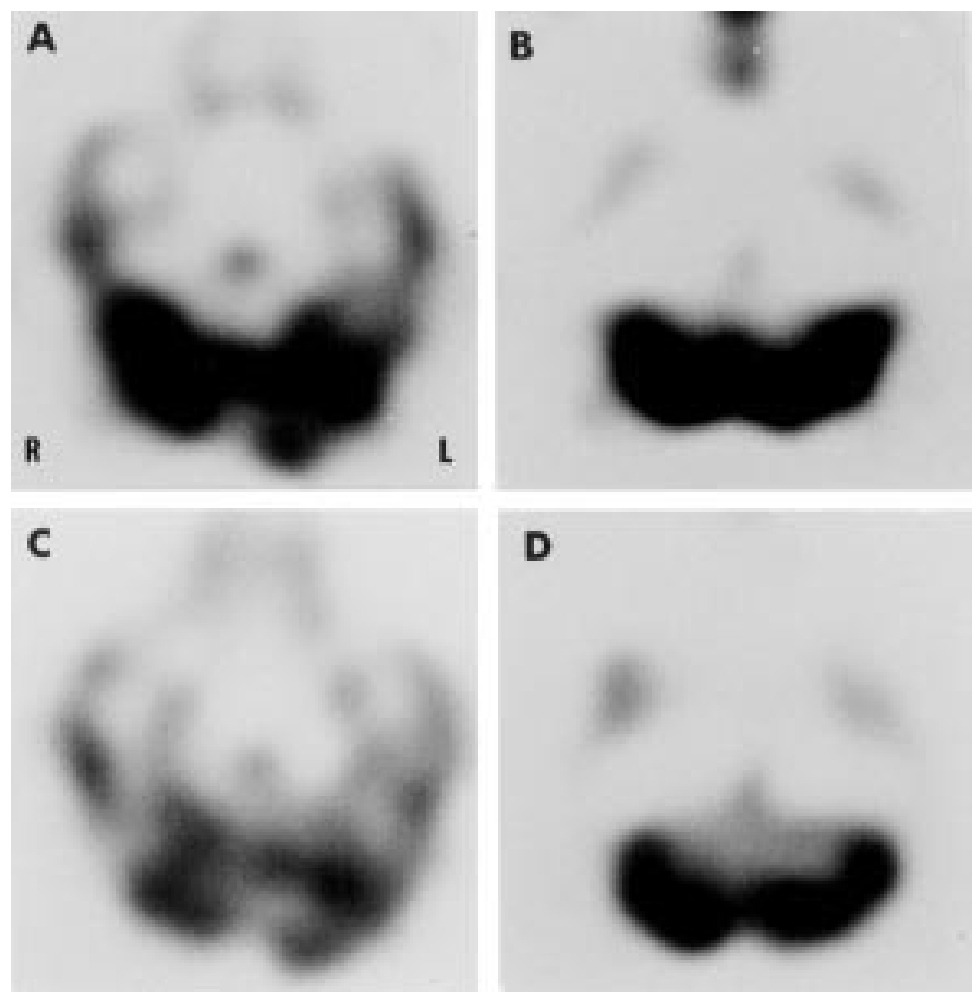

Figure 2 Technetium-99m hexamethylpropylene amine oxime SPECT without acetazolamide injection in patient 1 . An image taken during the attack shows hyperperfusion in (A) bilateral occipital cortices and (B) the cerebellum. A follow up image taken 28 days after onset of the attack shows normal cerebral blood flow in $(C)$ the occipital cortex and (D) the cerebellum. $R=$ right side of patient; $L=$ left side of patient.

10 hours after the amnesic period, the regional blood flow was not increased in any regions, and vasoreactivities to acetazolamide stress were normal in the first application of SPECT. In the second application, vasoreactivities to acetazolamide stress were normal in all regions of all patients.

\section{Case report (patient 1)}

The patient was a 57 year old right handed housewife with no relevant medical history. On 1 March 1994, she gardened until 1100 am and returned home for lunch. After lunch she began to ask family members why she was there and what she was doing there. Despite an answer to her questions, she repeated the questions. She could not recall what she had eaten for lunch an hour before. Her husband brought her to our hospital two hours after the onset of the disorder. The patient seemed very anxious and repeatedly asked why she was there. Her blood pressure was $124 / 78 \mathrm{~mm} \mathrm{Hg}$ and her pulse was regular at 68 beats per minute. Neurological examination was normal except for severe memory impairment. Her ability to retain new information was severely impaired. Verbal expression, comprehension, and immediate repetition of sentences and words were normal. Brain MRI was normal. Measurement of $\mathrm{CBF}$ using ${ }^{99 \mathrm{~m}} \mathrm{Tc}$ HMPAO was done three hours after the onset of the attack. In the six hours after the onset of amnesia, the patient regained her ability to retain new information and recovered completely. The results of CBF measurement showed abnormally high blood flow in the bilateral occipital cortices and cerebellar cortices. A follow up study done 28 days after onset showed that blood flow in the bilateral occipital cortices and cerebellar cortices had returned to normal. Figure 2 shows the SPECT images.

\section{Discussion}

The two patients examined during an attack and one patient examined five hours after recovery from amnesia showed increased CBF and three patients who were examined six to 10 hours after amnesic periods had decreased blood flow in some areas of the brain. These abnormalities in CBF, both increased and decreased, were transient and almost disappeared on application of follow up SPECT. Table 2 shows a review of previous reports concerning location and nature of the blood flow studies with SPECT or PET. Regional CBF during transient global amnesia has usually been reported to be decreased in the temporal lobe, ${ }^{17-22}$ thalamus, ${ }^{81}$ and frontal lobe. ${ }^{23} \mathrm{Re}-$ ports of increased regional CBF during an attack have been rare. ${ }^{14}$ However, most studies $^{717-20}$ used qualitative methods, with quantitative CBF studies being rare..$^{8917}{ }^{23} \mathrm{In}$ our quantitative study, the common regions that showed increased blood flow during an attack were the occipital cortex and cerebellum. There has been no report of changes in blood flow in the occipital cortex or the cerebellum during an attack by quantitative CBF measurement. Tanabe et $a l^{19}$ reported hypoperfusion in the posterior cerebral artery territory by $\left[{ }^{123} \mathrm{I}\right]( \pm) \mathrm{N}$-isopropyl-p-iodoamphetamine (IMP) distribution; however, the distribution of IMP seemed to be higher in the cerebellum during the attack than five months later. Evans et $a l^{20}$ reported hypoperfusion in the bilateral medial temporal lobes; however, their data, presented in a figure, also seemed to suggest hyperperfusion in the bilateral occipital cortices during an attack. Although none of these reports included quantitative measurements of $\mathrm{CBF}$, it is possible that $\mathrm{CBF}$ is increased in the cerebellum and occipital lobe during an attack.

Our results indicate that $\mathrm{CBF}$ in the cerebellum and occipital cortices is increased during the attack, then gradually decreases after an amnesic spell. The blood flows in the hippocampus and parahippocampal gyrus were normal during an attack. The occipital lobe, the cerebellum, and the medial aspects of the temporal lobe receive blood from the vertebrobasilar system, which is called the posterior circulation. ${ }^{25-27}$ Therefore, it is possible that the hippocampus and parahippocampal gyrus receive relatively decreased blood flow during an attack when compared to the increased blood flow in the cerebellum and occipital cortex. After an amnesic period, the changes in blood flow are transient and gradually disappear. Previous reports ${ }^{18-21}$ suggest there may also be a period of decreased CBF in the medial aspects of the temporal lobe soon after an onset of transient global amnesia. Therefore, it is possible that blood flow in the hippocampus and parahippocampal gyrus of patients with transient global amnesia may initially decrease at 


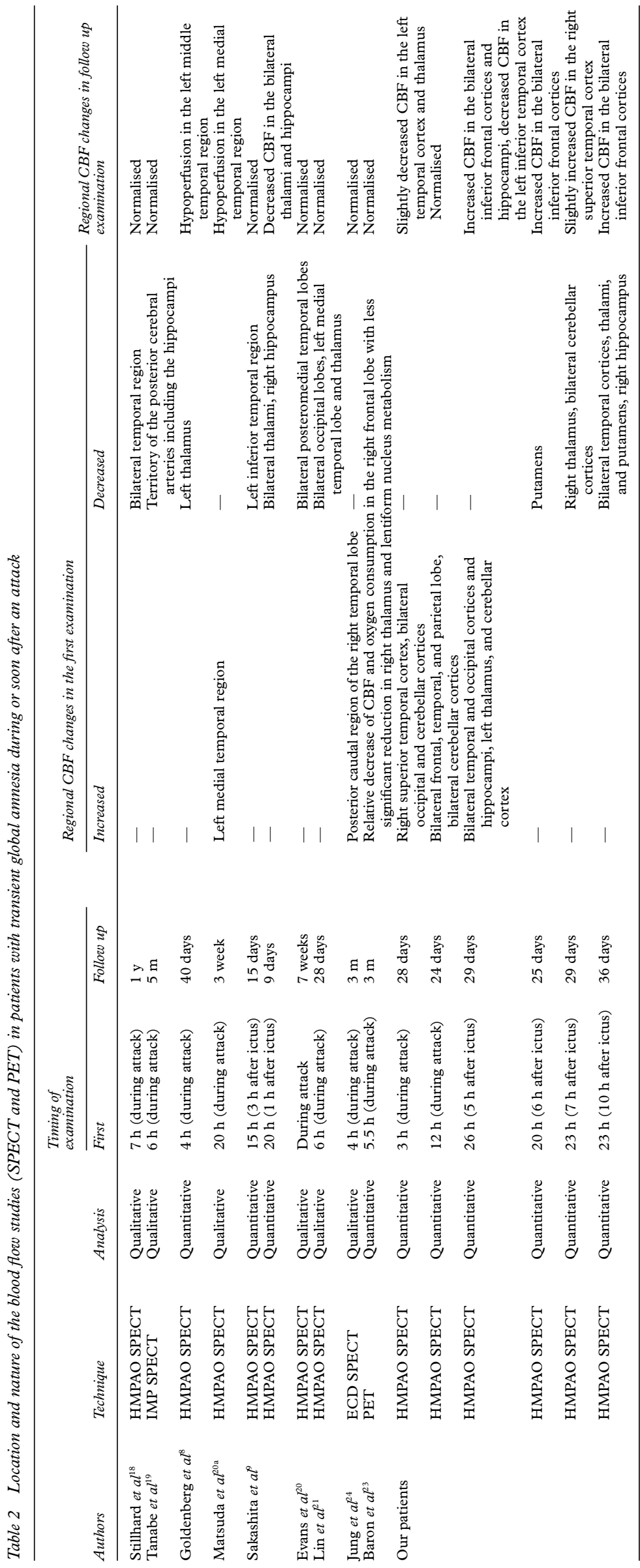

the onset of the attack and then the hippocampus and parahippocampal gyrus gradually regain normal blood flow during an attack with increased blood flow in the cerebellum and occipital cortices. Olesen $e t a l^{28}$ reported similar changes in $\mathrm{CBF}$ in patients with migraine. They concluded that the first event was a decrease in regional cerebral blood flow; thereafter, headache occurred while regional blood flow decreased. During the headache phase, regional blood flow gradually changed from abnormally low to abnormally high without apparent change in headache. Our findings indicate that transient global amnesia and migraine may share, at least in part, the same underlying mechanism. Melo et $a l^{29}$ in a case-control study showed that patients with transient global amnesia had significantly more migraine than normal subjects. Migrainous vasospasm may cause transient ischaemia of the brain structures that play important parts in memory and vascular dysfunction in the territory of the posterior cerebral artery could explain transient global amnesia. ${ }^{30}$ However, most patients with transient global amnesia have no history of migraine or of migrainous manifestations during an attack ${ }^{1}$ and Kushner et al found no connection between transient global amnesia and migraine in a case-control study. ${ }^{31}$ We consider that transient global amnesia is a distinct clinical entity, although it may share the same underlying vascular mechanism with migraine, because none of our patients had a history of migraine or migrainous manifestations during an attack. ${ }^{1}$

Some authors suggested that cortical spreading depression plays an important part in the underlying mechanism of migraine aura. ${ }^{32} 33$ Cortical spreading depression is a transient phenomenon that induces remarkable cerebrovascular disturbances including an initial hyperaemia with dilatation of pial arterioles followed by a long lasting hypoperfusion. ${ }^{34}{ }^{35} \mathrm{It}$ impairs autoregulation of cortical blood flow both transiently and reversibly. ${ }^{34}$ There are some similarities between blood flow changes in cortical spreading depression and the results of our study in transient global amnesia. Olesen et $a l^{36}$ hypothesised that transient global amnesia could be explained by the cortical spreading depression. Colonna et $a l^{35}$ reported that nitric oxide promoted arteriolar dilatation during cortical spreading depression. Cortical spreading depression and an increase in nitric oxide seem attractive candidates for the underlying mechanism of transient global amnesia; however, there is no direct evidence to support the hypothesis. Caplan ${ }^{5}$ proposed the concept of "acute arterial dyscontrol," postulating that such dyscontrol causes transient global amnesia by a transient self limited alteration of vascular tone in the posterior circulation. Our results seem to support Caplan's theory but the true mechanism of the dyscontrol remains unclear.

Regional CBF reactivity to acetazolamide is considered to represent an index of vascular reserve, because the extent of increase in regional CBF is determined by the condition of the vasculature. ${ }^{37}$ Our results showed that two 
patients examined during an attack had increased regional blood flow in the occipital cortex and cerebellum and that the vasoreactive response to acetazolamide was impaired in these regions. In the first examination of patient 3, the regional blood flow in the thalamus, hippocampus, and parahippocampal gyrus was decreased after the injection of acetazolamide, which suggested a steal phenomenon caused by impaired vasoreactivity in these regions. The cause of this finding was not an arteriosclerotic change because the vasoreactivity examined one month after onset showed no abnormality. We therefore suggest that vasoreactivity in the posterior circulation may be impaired during an attack. Although the mechanism for the impaired response to acetazolamide during an attack is not known, it is possible that a transient change that abolished the response to acetazolamide had occurred in the vertebrobasilar system, or that additional vasodilation was not possible, because remarkable vasodilation had occurred during the attack.

We thank Dr Hiroshi Matsuda, Department of Radiology, National Institute of Neuroscience, for his helpful advice. We are also indebted to the technicians in the Radiology Division of Tonami General Hospital for their technical support.

1 Kritchevsky M. Transient global amnesia. In: Boller F, Grafman J, eds. Handbook of neuropsychology. Vol 3. Amsterdam: Elsevier, 1989:167-82.

2 Fisher CM, Adams RD. Transient global amnesia. Acto Neurol Scand Suppl 1964;40:7-83.

3 Crowell GF, Stump DA, Biller J, McHenry LC, Toole JF. The transient global amnesia-migraine connection. Arch The transient global

4 Jackson A, Stewart G, Wood A, Gillespie JE. Transient global amnesia and cortical blindness after vertebral angiography: further evidence for the role of arterial spasm. $A m$ f Neuroradiol 1995;16:955-9.

5 Caplan LB. Transient global amnesia. In: Frederiks JAM, ed. Handbook of clinical neurology. Vol 1. Clinical neuropsychology. Amsterdam: Elsevier, 1985:205-18.

6 Fujii K, Sadoshima S, Ishitsuka T, Kusuda K, Kuwabara Y Ichiya Y, Fujishima M. Regional cerebral blood flow and metabolism in patients with transient global amnesia: a positron emission tomography study. 7 Neurol Neurosurg Psychiatry 1989;52:622-30.

7 Laloux P, Brichant C, Cauwe F, Decoster P. Technetium99m HM-PAO single photon emission computed tomography imaging in transient global amnesia. Arch Neurol 1992; 49:543-6.

8 Goldenberg G, Podreka I, Pfaffelmeyer N, Wessely P, Deecke L. Thalamic ischemia in transient global amnesia: Deecke L. Thalamic ischemia in transient glo

9 Sakashita Y, Sugimoto T, Taki S, Matsuda H. Abnormal cerebral blood flow following transient global amnesia. $\mathcal{F}$ Neurol Neurosurg Psychiatry 1993;56:1327.

10 Maren TH. Carbonic anhydrase: chemistry, pharmacology, and inhibition. Physiol Rev 1967;47:595-781.

11 Vorstrup S. Tomographic cerebral blood flow measurements in patients with ischemic cerebrovascular disease and evaluation of the vasodilatory capacity by acetazolamide test. Acta Neurol Scand Suppl 1988;114:1-48.

12 Højer-Pedersen E. Effect of acetazolamide on cerebral blood flow in subacute and chronic cerebrovascular disease. Stroke 1987;18:887-91.

13 Sakashita Y, Matsuda H, Kakuda K, Takamori M. Hypoperfusion and vasoreactivity in the thalamus and cerebellum after stroke. Stroke 1993;24:84-7
14 Matsuda $\mathrm{H}$, Tsuji S, Shuke N, Sumiya $\mathrm{H}$, Tonami N, Hisada K. Noninvasive measurements of cerebral blood
flow using technetium- $99 \mathrm{~m}$ hexamethylprophylene amine oxime. Eur f Nucl Med 1993;20:391-401.

15 Burt RW, Witt RM, Cikrit D, Cater J. Increased brain retention of Tc-99m HMPAO following acetazolamide administration. Clin Nucl Med 1991;16:568-71.

16 Knop J, Thie A, Fuchs C, Siepmann G, Zeumer H. ${ }^{99 \mathrm{~m}}$ Tc-HMPAO-SPECT with acetazolamide challenge to detect hemodynamic compromise in occlusive cerebrovascular disease. Stroke 1992;23:1733-42.

17 Trillet M, Croisile B, Philippon B, Vial C, Laurent B, Guillot $M$. Ictus amnésique et débits sanguins cérébraux. Rev Neurol (Paris) 1987;143:536-9.

18 Stillhard G, Landis T, Schiess R, Regard M, Sialer G. Bitemporal hypoperfusion in transient global amnesia: $99 \mathrm{~m}-\mathrm{Tc}-\mathrm{HM}-\mathrm{PAO}$ SPECT and neuropsychological findings during and after an attack. $\mathcal{F}$ Neurol Neurosurg Psychiatry 1990;53:339-42.

19 Tanabe H, Hashikawa K, Nakagawa Y, Ikeda M, Yamamoto $\mathrm{H}$, Harada $\mathrm{K}$, et al. Memory loss due to transient hypoperfusion in the medial temporal lobes including hippocampus. Acta Neurol Scand 1991;84:22-7.

20 Evans J, Wilson B, Wraight EP, Hodges JR. Neuropsychological and SPECT scan findings during and after transient global amnesia: evidence for the differential impairment of remote episodic memory. F Neurol Neurosurg Psychiatry 1993;56:1227-30.

20a Matsuda H, Higashi S, Tsaji S, Sumiya H, Miyauchi T, Hisada K, et al. High resolution Tc-99m HmPAO SPECT in a patient with transient global amnesia. Clin Nucl Med 1993;18:46-9.

21 Lin K, Liu R, Yeh T, Wang S, Liu H. Posterior ischemia during an attack of transient global amnesia. Stroke 1993;24:1093-5.

22 Volpe BT, Herscovitch P, Raichle ME, Hirst W, Gazzaniga MS. Cerebral blood flow and metabolism in human amnesia. F Cereb Blood Flow Metabol 1983;3(suppl 1):S5-6.

23 Baron JC, Petit-Taboué MC, Le Doze F, Desgranges B, Ravenel N, Marchal G. Right frontal cortex hypometabolism in transient global amnesia: a PET study. Brain 1994; 117:545-52.

24 Jung HH, Baumgartner RW, Burgunder JM, Wielepp JP, Lourens S, Wielepp JP. Reversible hyperperfusion of the right medial temporal lobe in transient global amnesia. $\mathcal{F}$ Neurol Neurosurg Psychiatry 1996;61:654-5.

25 Damasio H, Damasio AR. Road maps to neuroanatomy. In: Lesion analysis in neurophychology. New York: Oxford University Press, 1989:141-221.

26 Brust JCM. Stroke. Diagnostic, anatomical, and physiological considerations. In: Kandel ER, Schwartz JH, eds. Prin ciple of neural science. New York: Elsevier, 1983:667-79.

27 Hayman LA, Berman SA, Hinck VC. Correlation of CT cerebral vascular territories with function. II. Posterior cerebral artery. AfR Am f Roentgenol 1981;137:13-9.

28 Olesen J, Friberg L, Skyhøj Olsen T, Iversen HK, Lassen NA, Andersen AR, Karle A. Timing and topography of cerebral blood flow, aura, and headache during migraine attacks. Ann Neurol 1990;28:791-8.

29 Melo TP, Ferro JM, Ferro H. Transient global amnesia: a Melo TP, Ferro JM, Ferro H. Transient glo
case control study. Brain 1992;115:261-70.

30 Caplan L, Chedru F, Lhermitte F, Mayman C. Transient global amnesia and migraine. Neurology 1981;31:1167-70.

31 Kushner MJ, Hauser WA. Transient global amnesia: a casecontrol study. Ann Neurol 1985;18:684-91.

32 Lauritzen $M$. Pathophysiology of the migraine aura: the spreading depression theory. Brain 1994;117:199-210.

33 Woods RP, Iacoboni M, Mazziotta JC. Brief report: bilateral spreading cerebral hypoperfusion during spontaneous migraine headache. N Engl f Med 1994;331:1689-92.

34 Florence G, Bonvento G, Charbonne R, Seylaz J. Spreading depression reversibly impairs autoregulation of cortical blood flow. Am ₹ Physiol 1994;226:R1136-40.

35 Colonna DM, Meng W, Deal DD, Busija DW. Nitric oxide promotes arteriolar dilation during cortical spreading depression in rabbits. Stroke 1994;25:2463-70.

36 Olesen J, Jørgensen MB. Leao's spreading depression in the hippocampus explains transient global amnesia: a hypothesis. Acta Neurol Scand 1986;73:219-20.

37 Mountz JM, Deutsch G, Khan SH. Regional cerebral blood flow changes in stroke imaged by Tc-99m HMPAO SPECT with corresponding anatomic image comparison. Clin Nucl Med 1993;18:1067-82. 